\title{
RHEUMATOID ARTHRITIS AFFECTING THE HIP JOINT*
}

\author{
BY \\ E. N. GLICK, R. M. MASON, AND W. G. WENLEY \\ From the Departments of Physical Medicine and Regional Rheumatism Centres at the London Hospital \\ and Chase Farm Hospital, Enfield, Middlesex
}

Garrod (1890) gave a figure of $14 \cdot 6$ per cent. hip joint involvement in 500 patients with polyarthritis, and 6 years later Brabazon (1896) mentioned hip joint changes in 21 of 100 patients with rheumatoid arthritis. Coates and Delicati (1931) found sixteen patients with hip joint abnormalities in 100 consecutive cases at Bath. The statistical analysis of rheumatoid arthritis by Lewis-Faning (1950) showed hip joint changes in 16 per cent. of 532 patients. Forestier, Arlet, and Jacqueline (1951) found hipjoint involvement in 10 per cent. of their patients at the first examination, In a radiological study, Dilsen, McEwen, Poppel, Gersh, Di Tata, and Carmel (1962) found hip joint abnormalities in 33 per cent. of 89 rheumatoid arthritics, but these were a selected group of more severe cases. Weil, Perroy, and Guillon (1951) found hip arthropathy in 24 of thirty severely affected long-stay hospital in-patients with rheumatoid arthritis and, after excluding other aetiologies, nineteen out of 25 patients appeared to have rheumatoid arthritis of one or both hips. They stressed the relatively early onset of hip involvement and the frequency of acetabular protrusions and femoral head destruction. Estimates of the frequency of hip joint involvement in rheumatoid arthritis, therefore, lie between 10 and 33 per cent., but unfortunately none of these figures are satisfactory since either the diagnostic criteria were not defined or the series were selected.

\section{Material}

Patients.-We have analysed 279 consecutive patients at the London Hospital who were subjected to routine annual review either as out-patients or during in-patient treatment, during the period October, 1961, to December, 1962. All the patients satisfied the American Rheumatism Association criteria for "definite" rheumatoid

* Paper presented at a joint meeting of the Heberden Society and the Nederlands Vereniging van Rheumatogen at Groningen on May 17, 1963. arthritis (Ropes, Bennett, Cobb, Jacox, and Jessar, 1959) and were unselected except in so far as they had been referred to the hospital and were seen in our routine clinics.

In our departments all patients with rheumatoid arthritis are fully reviewed annually, or, if the arthritis is over 10 years in duration, every 2 years. The pelvic radiographs were taken at this time.

In addition, a further 79 patients were similarly assessed at Chase Farm Hospital but, as we considered that there was some selection of patients, these 79 have been included only in the analysis of radiographic features.

Juvenile patients with onset before the age of 16 year were excluded.

Controls.-Intravenous pyelogram films of 279 patients with genito-urinary disorders, balanced for age and sex with the main group, were examined in a similar manner.

\section{Method}

Assessment of $\mathbf{X}$ Rays.-All pelvic radiographs were examined at least twice by two observers at each analysis. When these two readings differed, a third reading was performed. To avoid bias, the control and rheumatoid arthritic radiographs were mixed and identified by numbers only and then were screened in such a way that it was not possible to distinguish control from rheumatoid films. Several $x$ rays of osteo-arthritic hips were also intermingled as an additional "anti-bias" measure.

In the $x$-ray study an attempt was made to discover which radiological features are typical of rheumatoid inflammatory involvement as opposed to degenerative changes occurring either with or without preceding rheumatoid involvement of the hip joint. The features recorded were loss of joint space, erosions, new bone formation, subchondral sclerosis, cyst formation, localized osteoporosis, protrusio acetabuli, deformity of the femoral head, and subluxation of the femoral head.

Assessments of all these features were made in four grades:

$$
\begin{aligned}
\text { I. } & \text { Doubtful } \\
\text { II. } & \text { Slight but definite } \\
\text { III. } & \text { Moderate } \\
\text { IV. } & \text { Severe }
\end{aligned}
$$


For loss of joint space a further grade of ankylosis was included.

Erosions were recorded only when an actual breach in the bony cortex was seen.

Circular translucencies adjacent to the joint space without any break in the bony cortex were recorded as cysts and, since it was often impossible to decide, no distinction was made between femoral and acetabular cysts.

Protrusio acetabuli and deformity of the femoral head were recorded as a visual impression only. No actual measurements were made and very minor degrees were not recorded.

In the light of our findings, five radiological diagnoses were made.

(1) No Arthropathy.-No feature of Grade II, III, or IV severity was seen.

(2) Degenerative Changes Only.-New bone formation and subchondral sclerosis were of the same grade as loss of joint space, especially when this was localized in the upper outer segment.

(3) Rheumatoid Changes Only.-New bone formation and sclerosis were Grade II or less and loss of joint space was uniform around the joint or was most marked in the upper inner part of the joint, giving the appearance of the femoral head burrowing into the acetabulum.

(4) Rheumatoid plus Degenerative Changes.-Joint narrowing was generalized and predominantly affected the upper and inner segment but was associated with new bone formation and sclerosis of Grade III or IV.

(5) Unclassified Arthropathy.-There was isolated loss of joint space and it was not possible to decide whether the changes were due to a degenerative or an inflammatory process.

\section{Incidence of Hip Arthropathy}

197 of the 279 rheumatoid patients ( 71 per cent.) had normal $x$ rays and 82 films ( 29 per cent.) showed abnormalities in one or both hips. 122 joints (22 per cent.) were affected (Table I).

TABLE I

RADIOLOGICAL FINDINGS

(279 cases)

\begin{tabular}{|c|c|c|c|c|}
\hline \multicolumn{3}{|c|}{ Findings } & No. & Per cent. \\
\hline No arthropathy & $\cdots$ & $\cdots$ & 197 & 71 \\
\hline Abnormalities & $\begin{array}{l}\text { Patients } \\
\text { Hip Joints }\end{array}$ & $\cdots$ & $\begin{array}{r}82 \\
122\end{array}$ & 29 \\
\hline \multicolumn{3}{|c|}{ Rheumatoid Changes Only } & 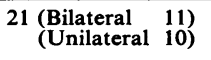 & 7 \\
\hline \multicolumn{3}{|c|}{ Degenerative Changes Only } & $15 \underset{\text { (Unilateral }}{\text { (Bilateral }}$ 10) & 5 \\
\hline
\end{tabular}

In 21 patients ( 7 per cent.), the changes were regarded as "rheumatoid only"; of these eleven were bilateral.

In fifteen patients ( 5 per cent. of the series), the radiological findings were considered to be "degenerative only"; five of these were bilateral.

Of the 122 abnormal hips (Table II), 36 (30 per cent.) showed rheumatoid changes only, 22 (18 per cent.) were degenerative in character, 27 (22 per cent.) showed both inflammatory and degenerative changes, and in 37 ( 30 per cent.) it was not possible to decide whether the changes were degenerative or inflammatory in nature.*

TABLE II

RADIOLOGICAL FINDINGS IN 122 ABNORMAL HIP JOINTS

\begin{tabular}{|c|c|c|c|c|c|}
\hline \multicolumn{4}{|c|}{ Changes } & No. & Per cent. \\
\hline $\begin{array}{l}\text { Rheumatoid Only } \\
\text { Degenerative Only } \\
\text { Mixed } \\
\text { Unclassified } \ldots\end{array}$ & $\begin{array}{l}\cdots \\
\cdots \\
\cdots\end{array}$ & $\begin{array}{l}\cdots \\
\cdots \\
\cdots\end{array}$ & \begin{tabular}{l|}
$\cdots$ \\
$\cdots$ \\
$\cdots$
\end{tabular} & $\begin{array}{l}36 \\
22 \\
27 \\
37\end{array}$ & $\begin{array}{l}30 \\
18 \\
22 \\
30\end{array}$ \\
\hline $\begin{array}{l}\text { Femoral Head Def } \\
\text { Protrusio acetabuli } \\
\text { Deformity }+ \text { Protr }\end{array}$ & $\begin{array}{l}\text { ormity } \\
\text { usion }\end{array}$ & $\begin{array}{l}\cdots \\
\cdots\end{array}$ & $\begin{array}{l}\ldots \\
\ldots \\
.\end{array}$ & $\begin{array}{r}22 \\
11 \\
7\end{array}$ & $\begin{array}{r}18 \\
9 \\
6\end{array}$ \\
\hline
\end{tabular}

Deformity of the femoral head was observed in 27 hip joints (22 per cent. of the abnormals) and protrusio acetabuli in eleven joints ( 9 per cent.). Both abnormalities were seen together in seven hip joints (6 per cent.).

In the control series of 279 I.V.Ps, twelve (4 per cent.) had radiological abnormalities of the hip joints; ten films showed degenerative arthropathy and two unclassified changes.

\section{Findings}

Our study revealed radiographic evidence of hip joint involvement in 29 per cent. of a representative sample of patients attending a regional rheumatism centre with "definite" rheumatoid arthritis. This is a high figure though, if symptoms and signs of hip joint abnormality were included, some evidence of hip joint abnormality could be found in 41 per cent. of this series. Mild arthropathy is frequently overlooked by both patient and physician because of more severe joint symptoms elsewhere.

5 per cent. of our patients had hip joint changes which were purely degenerative in appearance.

- In some cases with bilateral arthropathy, different radiological diagnoses were made for each hip joint. 
This is similar to the incidence of degenerative changes in the control series (4 per cent.).

Age and Duration of Disease.-One of us has previously shown (Glick, 1963) that rheumatoid arthritics with hip joint involvement tend to be a little older than those with normal hips and also tend to have had the disease for a longer time. These two factors tend to co-exist in longer-standing cases.

Table III correlates duration of disease, age of patient, and radiological hip joint abnormalities. Disease duration was divided into four groups: under 5 years, 5 to 10 years, 10 to 15 years, and over 15 years. The age groups were under 35 , 36 to 45,46 to 55,56 to 65 , and over 65 years. Analysing the two aspects simultaneously, twenty possible combinations arise and the percentage showing hip joint abnormalities are recorded for each of these sub-groups. In this analysis, whereas there was no obvious trend for the percentage to be higher in the more chronic cases of the same age group, there was a definite trend for involvement to be found more frequently in the older age groups.

TABLE III

PERCENTAGE RADIOLOGICAL INVOLVEMENT

(279 cases)

\begin{tabular}{l|c|c|c|c|c}
\hline \multirow{2}{*}{ Age yrs) } & \multicolumn{3}{|c|}{ Duration of Disease (yrs) } & \multirow{2}{*}{ Whole Group } \\
\cline { 2 - 5 } & Under 5 & $5-10$ & $10-15$ & Over 15 & \\
\hline Under 35 & 15 & 0 & 0 & 0 & 10 \\
$36-45$ & 25 & 0 & 23 & 0 & 17 \\
$46-55$ & 46 & 15 & 40 & 41 & 34 \\
$56-65$ & 27 & 32 & 33 & 44 & 33 \\
Over 65 & 55 & 47 & 62 & 36 & 50 \\
\hline Whole Group & 35 & 24 & 39 & 39 & \\
\hline
\end{tabular}

Forestier and others (1951) stated that hip involvement was usually seen late in the disease. In only five of their forty cases did it start in the first 5 years. Weil and others (1951) described thirty patients in six of whom hip arthropathy began in the first 5 years. Our series included 79 patients whose rheumatoid arthritis was of less than 5 years' duration and 28 of these had some $x$-ray abnormality ( 35 per cent.). This very high incidence agrees with the finding that 33 patients developed hip symptoms before the end of the fifth year. Our experience is, therefore, that hip involvement is frequently an early feature of the disease.

Sex.-As shown in Table IV, there were differences between males and females. (The figures refer to the larger series of 358 cases.) Degenerative changes were much more common in men (12 per cent.) than in women ( 2 per cent.), whereas inflammatory changes were more frequent in women (12 per cent.) than in men (6 per cent.). Deformity of the femoral head and protrusio acetabuli were each more common among female patients (8 and 4 per cent.) than among males ( 5 and 2 per cent.).

TABLE IV

RADIOLOGICAL FINDINGS

(358 cases)

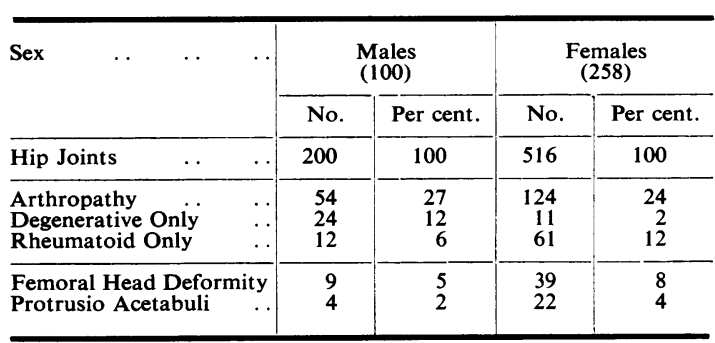

Radiological Features.-In the full series of 358 cases, 199 hip joints showed definite abnormalities (Table V).

TABLE V

RADIOLOGICAL FEATURES

(358 cases)

\begin{tabular}{|c|c|c|c|c|c|}
\hline \multirow{2}{*}{\multicolumn{4}{|c|}{ Observations }} & \multicolumn{2}{|c|}{ Hips } \\
\hline & & & & \multirow[b]{2}{*}{$\begin{array}{r}\text { No. } \\
199 \\
153 \\
53 \\
21 \\
90 \\
58 \\
50 \\
15 \\
4 \\
48 \\
26\end{array}$} & \multirow[b]{2}{*}{$\begin{array}{c}\text { Per cent. } \\
100 \\
77 \\
27 \\
11 \\
45 \\
29 \\
25 \\
8 \\
2 \\
24 \\
13\end{array}$} \\
\hline $\begin{array}{l}\text { Definite Arthropathy } \\
\text { Loss of Joint Space } \\
\text { Erosions . . . } \\
\text { Localized Osteoporosis } \\
\text { Subchondral Sclerosis } \\
\text { Osteophytosis . . } \\
\text { Subchondral Cysts } \\
\text { Subluxation . . } \\
\text { Ankylosis . . . . } \\
\text { Destruction of Femoral } \\
\text { Protrusio Acetabuli }\end{array}$ & $\begin{array}{l}\cdots \\
\cdots \\
\cdots \\
\cdots \\
\cdots \\
\cdots \\
\cdots \\
\text { Head } \\
\cdots\end{array}$ & $\begin{array}{l}\cdots \\
\cdots \\
\cdots \\
\cdots \\
\cdots \\
\cdots \\
\cdots \\
\cdots\end{array}$ & \begin{tabular}{l|}
$\cdots$ \\
$\cdots$ \\
$\cdots$ \\
$\cdots$ \\
$\cdots$ \\
$\cdots$ \\
$\cdots$ \\
$\cdots$ \\
$\cdots$ \\
$\cdots$
\end{tabular} & & \\
\hline
\end{tabular}

Loss of Joint Space.-This was the most consistent feature, and occurred in 77 per cent. of these abnormal joints.

Erosions.-These were recorded less frequently; in 27 per cent. of the abnormals. They were rarely clearly-defined, as in the hands. An unusually clear example is seen in Fig. 1 (opposite).

Localized Osteoporosis.-This was not very common (10 per cent.) and rarely striking (Fig. 2, opposite). 


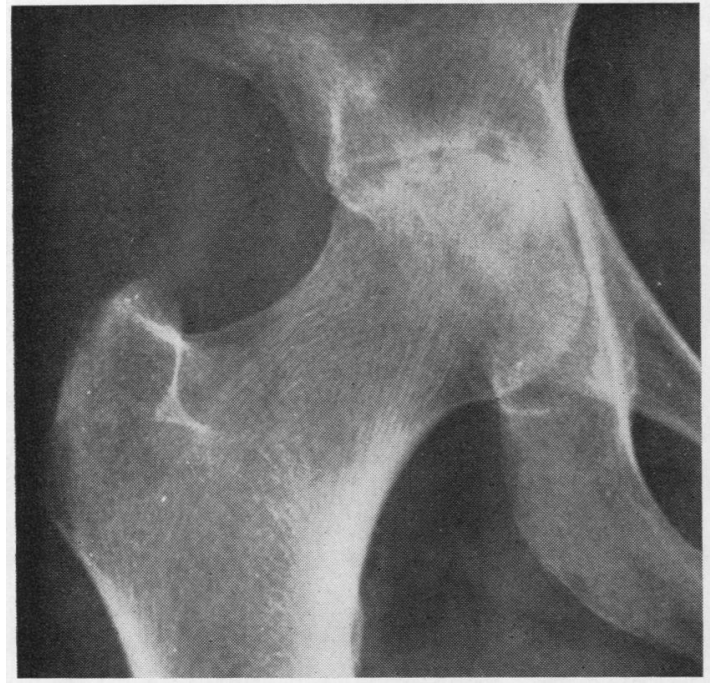

Fig. 1.-Erosions: Generalized loss of joint space (Grade IV) and erosions (Grade III).

Sclerosis of the Subchondral Bone.-This was the second most common radiological sign ( 45 per cent.), seen particularly in the upper weight-bearing part of the acetabulum. It was usually associated with more gross abnormalities and was recorded as a degenerative change.

New Bone Formation.-This was most frequently seen at the acetabular rim and occurred in 29 per cent. of the abnormals; it was occasionally found as the only abnormality. It was always regarded as degenerative in nature (Fig. 3).

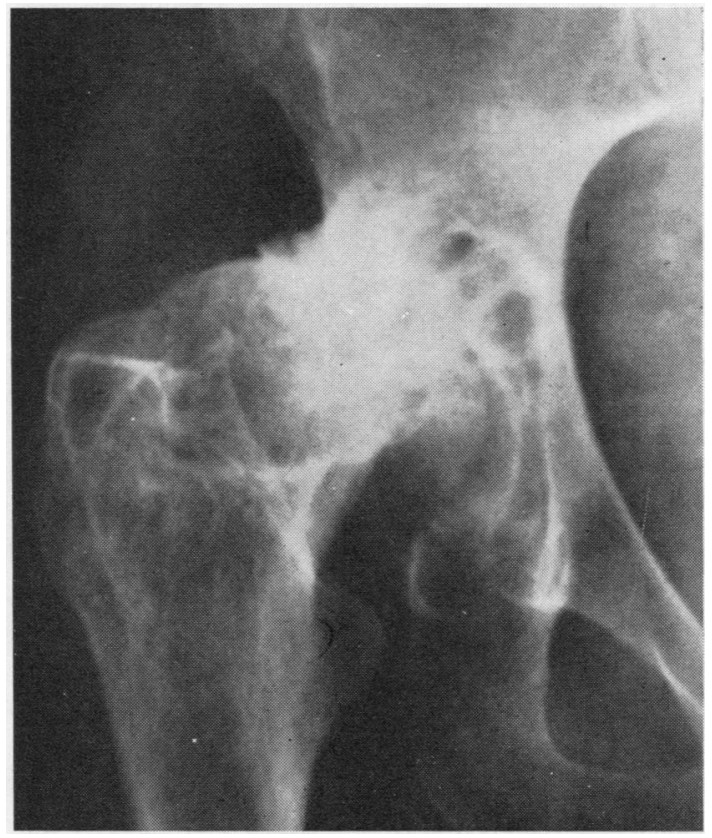

Fig. 3.-Degenerative Arthropathy: Typical changes in a patient with rheumatoid arthritis, most marked in the outer segment of the joint. Note "mushroom deformity" of femoral head (Type $i$ ).

Cyst-like Apprarances.-These were recorded in 25 per cent. of the abnormal hips. They were

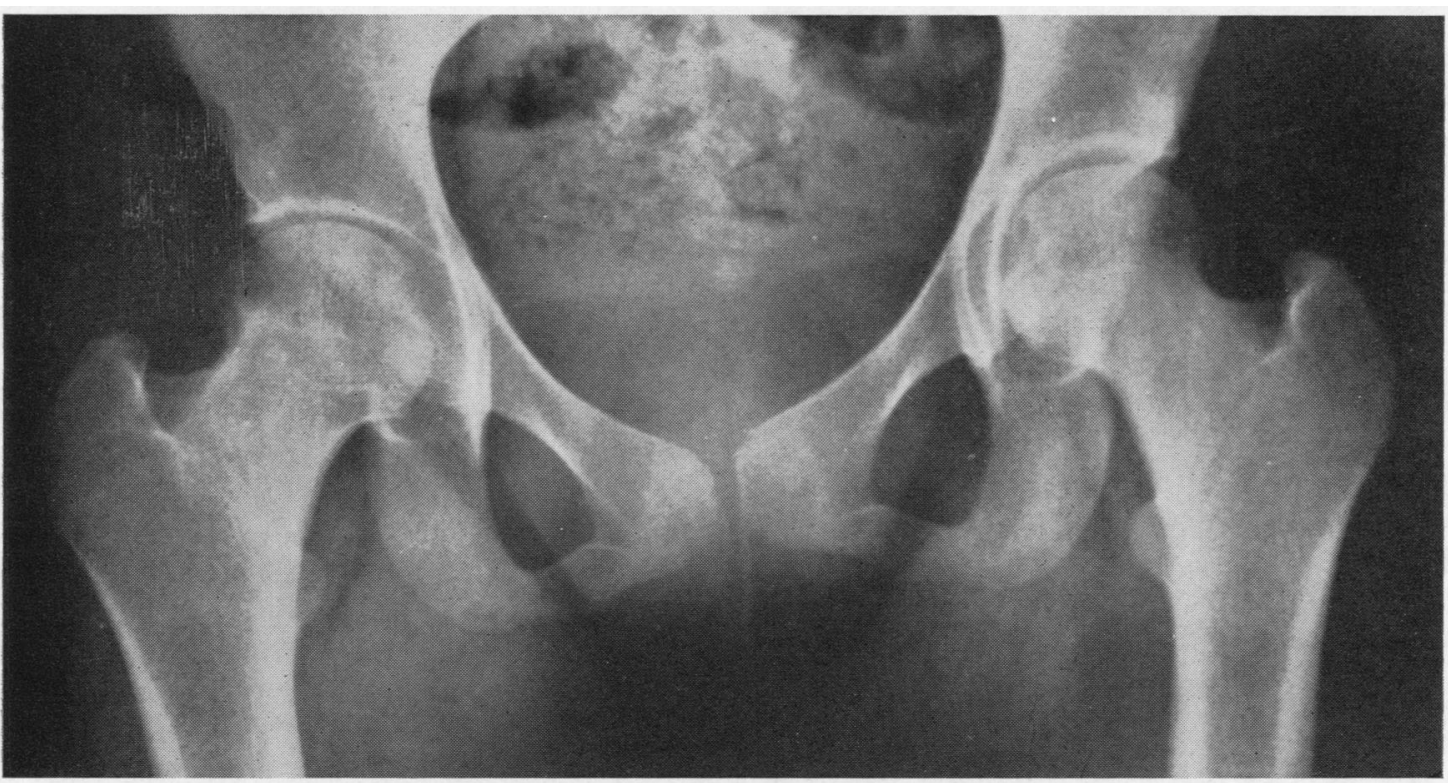

Fig. 2.-LOCALIZED Osteoporosis: Very early changes in the right hip joint. Grade II loss of joint space and osteoporosis. 


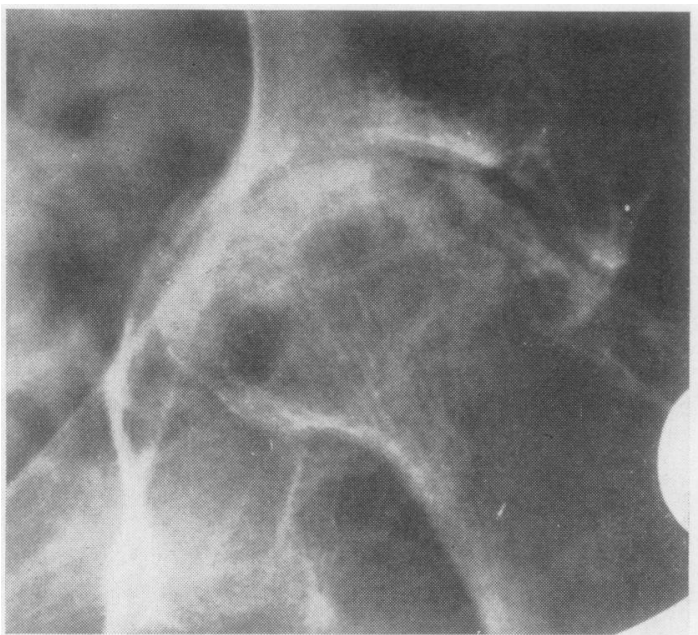

Fig. 4(a).-CySTS: Deformity of femoral head with cystic changes apparently in the femur.

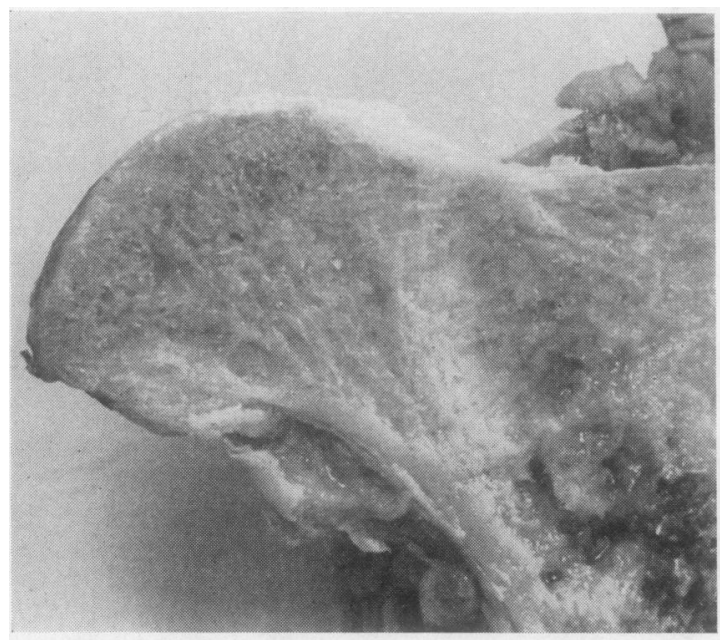

Fig. $4(b)$.- Section of femoral head showing smooth surface and absence of cysts.

regarded as indicating a more marked degree of involvement but their significance in differentiating degenerative from inflammatory changes was not ascertained and their evaluation proved difficult. Fig. $4(a, b$, and $c)$ illustrates that cystic changes which appear on straight radiography to be in the femoral head, may in fact be in the acetabulum.

Subluxation of the Femoral Head.-This was seen in 7.5 per cent. of the abnormals. It was usually associated with deformity either of the femoral head or of the acetabular shelf (Fig. 5, opposite).

Bony Ankylosis. - This was recorded in only 2 per cent. Often on other films no joint space at

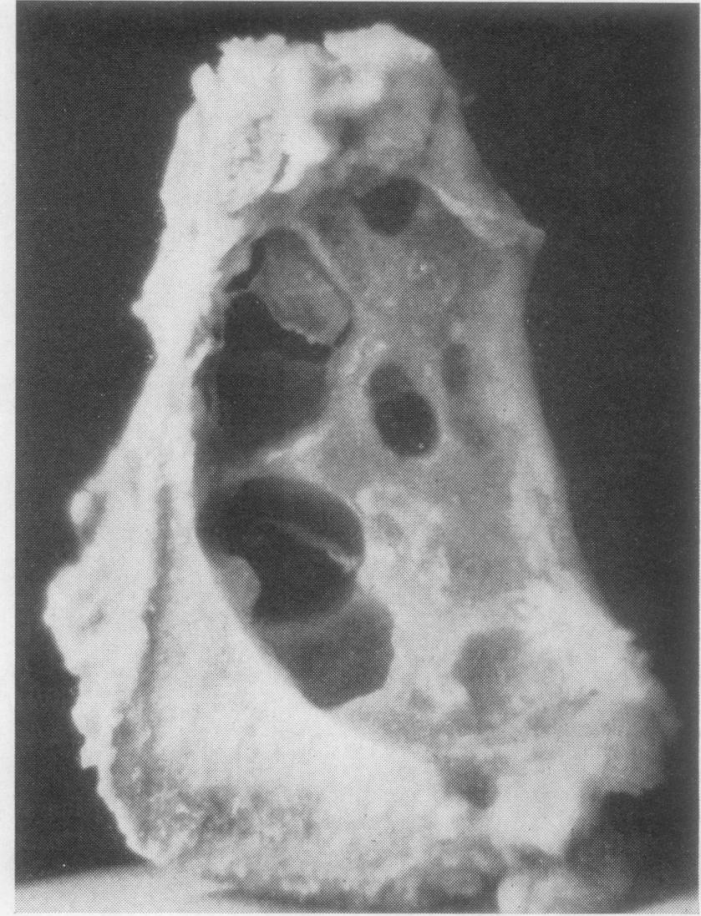

Fig. 4(c).-Section of acetabulum showing articular surface partially replaced by large cavities.

all could be seen, but the bony trabeculae did not run across the joint region.

Deformity of the Femoral Head.-This was observed in one quarter of the affected hip joints. In eleven patients it was bilateral and in 26 unilateral. Three forms were seen:

(i) This was generally mild and consisted of a flattening or indentation of the upper and outer segment of the head. The cortical line was intact. This change is frequently seen in osteo-arthritic joints where it may progress to "mushrooming" of the head (Fig. 3).

(ii) This was a destructive erosive process similar to that seen in the hands and there was frequently associated erosive destruction of the acetabulum (Fig. 6, opposite).

(iii) This frequently produced the most severe femoral head deformities, taking the form of a rapid and progressive crumbling of the head as though from necrosis or bone resorption (Fig. 7, opposite).

Protrusio Acetabuli.-This occurred in 13 per cent. of the rheumatoid hip joints. Nine patients had bilateral changes and eight unilateral protrusion. 


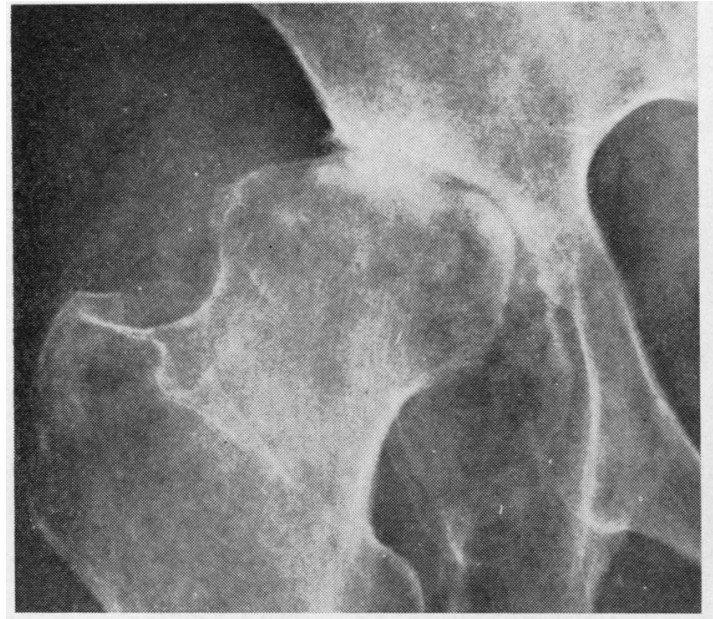

Fig. 5.-Subluxation: Grade III subluxation associated with Grade III femoral head deformity (Type $i$ ) and destruction of the acetabular shelf.

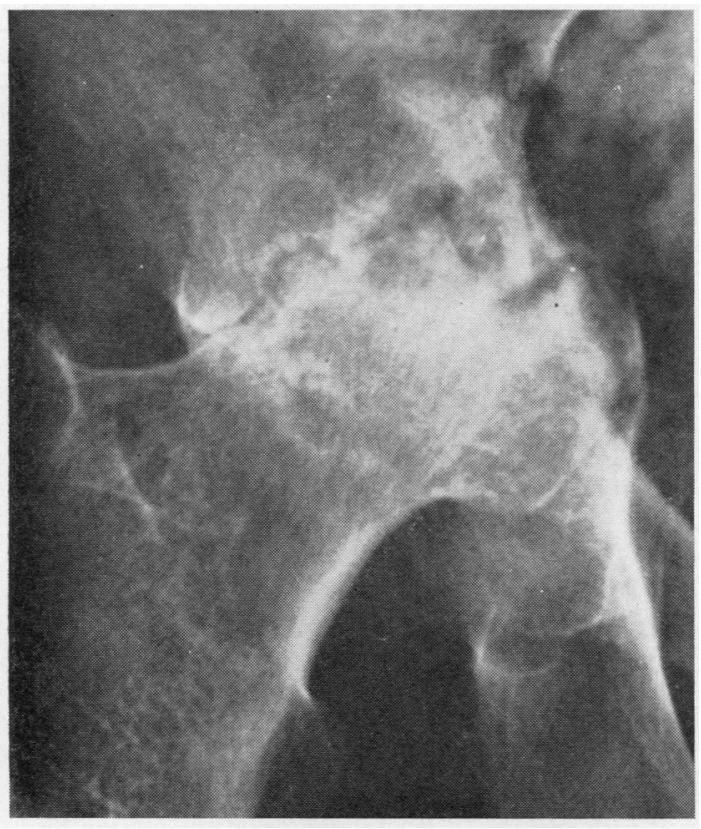

Fig. 6.-Destruction of Femoral Head by erosions (Type ii).

In four bilateral and seven unilateral cases, protrusion and femoral head deformity were associated (Fig. 8).

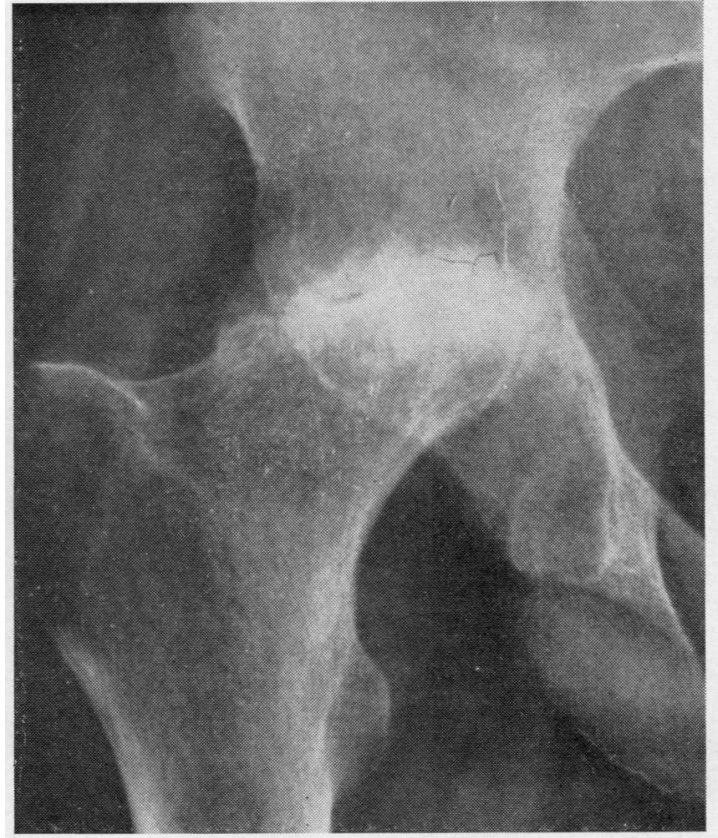

Fig. 7.-Femoral Head Deformity (Grade IV): Previous films showed rapidly progressive deformity without erosions (Type iii).

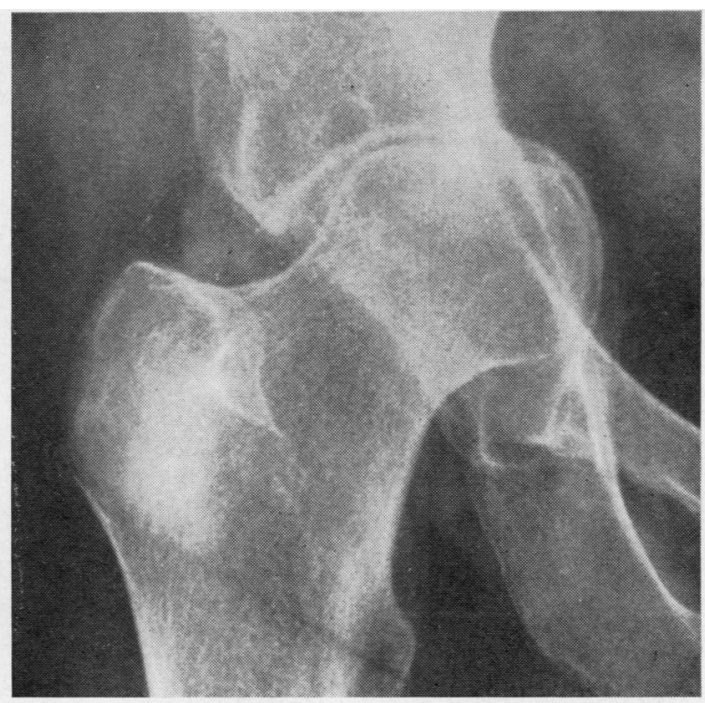

Fig. 8.-Protrusio Acetabuli (Grade IV) with femoral head deformity.

\section{Discussion}

Localized osteoporosis and erosions, although found in the hip joint, were uncommon and often difficult to see. Tomography is often helpful in 
visualizing the joint changes and elucidating cystlike appearances, but it is doubtful whether this investigation is worthwhile as a routine measure. The pattern of joint narrowing is the most distinctive rheumatoid change in the hip. Whereas the outer segment of the hip joint is predominantly affected in degenerative arthritis, in rheumatoid arthritis the changes are most marked in the upper and inner part of the joint. Loss of cartilage here gives a characteristic appearance of the femoral head burrowing into the pelvis even without protrusion of the acetabulum (Fig. 9).

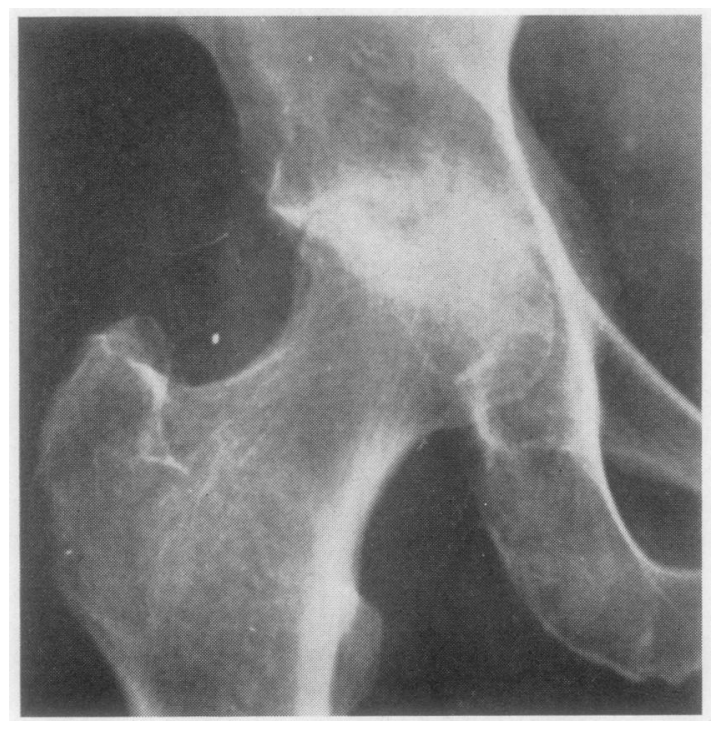

Fig. 9.-Loss of JoINT SPACE (Grade IV): Characteristically most marked in the upper inner part of the joint.

McEwen, Poppel, Poker, and Jacobson (1956) found protrusio acetabuli in five out of 100 patients with rheumatoid arthritis of the hip; including a sixth case, they had three males and three females. Amongst our patients, this complication was observed in seven out of 82 ( 9 per cent.) cases in the London Hospital series and in seventeen out of 168 (10 per cent.) in the larger series despite our adopting stricter criteria. However, Forestier and others (1951) noted this feature in 20 per cent. of their patients with rheumatoid arthritis of the hip, and three of their eight cases were bilateral.

Reviewing pelvic $x$ rays of approximately 300 rheumatoid arthritics, Isdale (1962) found ten females and five males with collapse of the femoral head (ten of these also had protrusio acetabuli), whereas 22 of our 279 London Hospital patients and 37 of the 358 patients in our combined series showed this abnormality. It occurred in 5 per cent. of the male and 8 per cent. of the female hip joints. Femoral head deformity was thus observed in 24 per cent. of our series of rheumatoid hips. The "osteolytic" form of hip change has been described in detail by Piguet (1956) who also discussed its relationship to femoral head necrosis.

Forestier and others (1951) described four radiological stages of hip joint involvement:

(i) "Minimal Arthritis", characterized by narrowing of the upper inner part of the joint space with or without juxta-articular osteoporosis.

(ii) "Established Arthritis", in which the joint narrowing was more marked and there was alteration of the bone pattern, which was slightly mottled and rarefied, the articular surfaces being irregular.

(iii) "Destructive Arthritis", characterized by alteration of the shape of the head and the acetabulum, with irregularity of the opposing joint surfaces and some enlargement of the acetabulum.

(iv) "Secondary Acetabular Protrusion", the most striking feature being protrusio acetabuli, usually with deformity of the femoral head which may have been so destroyed as to present the appearance of a battant de cloche-a bell-clapper.

A fifth radiological picture was termed "coxite densifiante". Here there was sclerosis of both joint margins with some narrowing and perhaps irregu larity but no evidence of progression. This wase considered to be a burnt-out form.

All these $x$-ray appearances were observed in our series. We have been impressed by the fact that although Stages (iii) and (iv) constitute an advanced form of the disease, they are not necessarily a late stage and may be seen within the first few years of the rheumatoid arthritis. We have also noted an appreciable number of cases in which the maximal joint changes were in the upper outer segment: typically the site of degenerative changes.

\section{Conclusion}

We consider that the most characteristic $x$-ray appearance of rheumatoid arthritis of the hip joint is loss of joint space which, although generalized, is more marked in the upper inner segment. Even in the presence of secondary sclerosis and new bone formation, the appearance of the femoral head burrowing into the pelvis is easily recognizable and is quite distinctive from the appearance of severe primary osteo-arthritis (Fig. 10, opposite).

\section{Summary}

Radiological abnormalities were found in one or both hips of 29 per cent. of 279 consecutive patients 


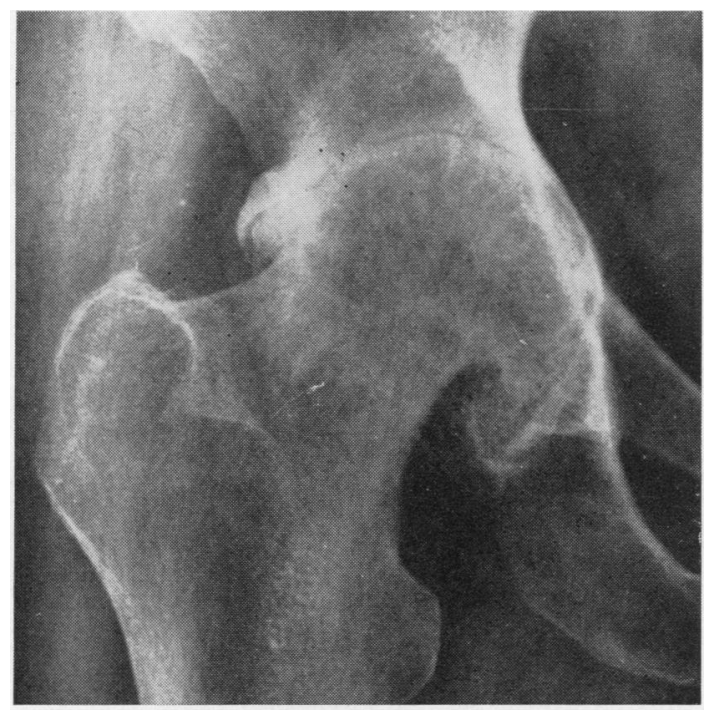

Fig. 10.-MiXed ARTHROPATHY: Despite the new bone formation, the burrowing of the femoral head into the pelvis suggests a primary rheumatoid aetiology.

with rheumatoid arthritis. Only 4 per cent. of a balanced control series of intravenous pyelogram films showed abnormalities of the hip joints. The percentage involved was greater in the older age groups, but within the same age group patients with a longer duration of disease did not have a significantly higher rate of hip arthropathy. Typical degenerative changes were more common among the males, whereas destruction of the femoral head and protrusio acetabuli were more common among the females.

The typical radiological features as observed in a larger series of 358 patients are described.

We wish to thank Dr. W. S. Tegner and Dr. V. L. Steinberg, for allowing us to include patients under their care in this study, the other members of our departments who co-operated in the work, and Dr. J. W. Landells for the pathological specimen. We are grateful to our Records Officer, Miss P. M. Birleson, for her invaluable assistance in the numerical analysis and to Mr. R. F. Ruddick and Miss P. Burgess for the illustrations.

\section{REFERENCES}

Brabazon, A. B. (1896). Brit. med. J., 1, 723.

Coates, V., and Delicati, L. (1931). "Rheumatoid Arthritis and its Treatment". Lewis, London.

Dilsen, N., McEwen, C., Poppel, M., Gersh, W. J., DiTata, D., and Carmel, P. (1962). Arthr. and Rheum., 5, 341.

Forestier, J., Arlet, J., and Jacqueline, F. (1951). Rev. Rhum., 18, 304.

Garrod, A. E. (1890). "A Treatise on Rheumatism and Rheumatoid Arthritis". Griffin, London.
Glick, E. N. (1963). Ann. phys. Med. (In the press.)

Isdale, I. C. (1962). Ann. rheum. Dis., 21, 23.

Lewis-Faning, E. (1950). Ibid., 9, Suppl.

McEwen, C., Poppel, M. H., Poker, N., and Jacobson, H. G. (1956). Radiology, 66, 33.

Piguet, B. (1956). Sem. Hôp. Paris, 32, 2483.

Ropes, M. W., Bennett, G. A., Cobb, S., Jacox, R., and Jessar, R. A. (1959). Ann. rheum. Dis., 18, 49.

Weil, M. P., Perroy, A., and Guillon, J. (1951). Rev. Rhum., 18, 516.

Discussion.--It was suggested that bony ankylosis was rare and occurred only with ankylosing spondylitis.

Prof. E. G. L. Bywaters (Taplow), commenting that protrusio acetabuli was mainly bilateral, suggested that there was some predisposition which determined bilaterality.

DR. A. G. S. HiLl (Stoke Mandeville) suggested that, if the disease was unilateral, the patient does not bear weight on the affected side and hence there was no protrusion.

DR. MASON said that advanced destruction with protrusion could occur in bedridden patients.

Arthrite rhumatismale affectant l'articulation de la hanche

\section{RÉSUMÉ}

Des anomalies radiologiques furent trouvées dans une ou les deux hanches dans 29 pour cent des 279 malades consécutifs atteints d'arthrite rhumatismale. Une série ajustée, servant de témoin, de clichés de pyélogrammes ne révéla que 4 pour cent d'anomalies articulaires de la hanche. Ces pourcentages furent plus élevés dans des groupes d'âge plus avancé, mais parmi les malades d'un âge similaire la durée de la maladie n'affectait pas appréciablement l'arthropathie de la hanche. Des altérations dégénératives typiques furent plus communes parmi les hommes, tandis que la destruction de la tête fémorale et la protrusion acétabulaire furent plus communes chez les femmes.

On décrit les caractères radiologiques typiques, observés dans une série plus grande de 358 malades.

\section{Artritis reumatoide afectando la articulación de la cadera}

\section{SUMARIO}

Anomalías radiológicas fueron encontradas en una o ambas caderas en un 29 por ciento de 279 enfermos consecutivos con artritis reumatoide. Una serie testigo ajustada de clisés de pielogramas reveló sólo un 4 por ciento de anomalías articulares de la cadera. Estos porcentajes fueron mayores en grupos de enfermos de edad más adelantada, pero dentro de los grupos de edad similar la duración de la enfermedad no afectaba significativamente la artropatía de la cadera. Alteraciones degenerativas típicas fueron más comunes en los hombres, mientras que la destrucción de la cabeza femoral y la protrusión acetabular fueron más comunes en las mujeres.

Se describen los rasgos radiológicos típicos, basados en la observación de una mayor serie de 358 enfermos. 